\section{The hospital drawings of Barbara Hepworth}

\author{
John Launer
}

"Ladies and gentlemen, I must ask you to be patient with my deficiencies as a speaker - I have never spoken in public before and would not have attempted to speak about 'the artist's view of surgery' but for the fact that to refuse seemed ungracious when I, myself, owe so much to the kindness and generosity and help on the part of many surgeons who made my studies in the operating theatre possible." 1 The speaker here was Barbara Hepworth, one of the greatest British sculptors of the twentieth century. She was addressing a group of surgeons in Exeter in 1953. The 'studies' she mentioned were some remarkable drawings she had made in operating theatres for a few years following the second world war. As she explained during her presentation: "From the first moment I was entirely enthralled by the classic beauty of what I saw there; classic in the sense that architecture and function were perfectly blended and purity of idea and grace of execution were in complete harmony."

Hepworth's vision of the aesthetic beauty of surgery arose from a chance encounter and the close friendship that developed from this. In 1944 her daughter Sarah - one of triplets - acquired osteomyelitis and was admitted to a small hospital in Cornwall, where the family lived. There she was visited by an orthopaedic surgeon named Norman Capener, who transferred Sarah to his own hospital in Exeter. Capener was an amateur painter, and Hepworth invited him to visit the studio that she shared with her husband Ben Nicholson. Hepworth became interested in hospital design and urged him to add more colour to the hospital wards. Then, in 1947, while Capener was recovering from an illness, she encouraged him to take up carving stone. From this conversation, the idea arose that she herself should observe and draw the work of surgeons in action.

During the following three years, Hepworth sat in on operations carried out by Capener and his team, and also by two other surgeons: the ear, nose and throat surgeon Edward Garnett Passe, and another orthopaedic surgeon called Reginald Watson-Jones. On her visits, she would sometimes stay in the theatre for up to ten hours. Altogether, Hepworth made over 70 drawings, using ink, chalk or pencil on paper, or using a variety of different implements to inscribe on a background of gesso - a mixture of enamel paint, chalk and white lead.

\section{SPIRITUAL ATMOSPHERE}

Even for admirers of Hepworth's sculpture, the drawings are breathtaking. They certainly equal her far more famous masterpieces in wood, metal and stone. They may have been inspired by the recent creation of the National Health Service, of which she was a passionate supporter, ${ }^{2}$ and this is possibly reflected in the altruism she portrays in the doctors and nurses. The solidity of the drawn figures echoes her three-dimensional work, and also recalls great Renaissance painters like
Masaccio. Above all, the drawings evoke an atmosphere of spirituality. Every one of them is a portrait of reverence and contemplation. Some of them - no doubt intentionally - resemble familiar biblical themes. "Concentration of Hands I" figure 1 is set out like a painting of the Christian holy family, with the nurse bearing a close similarity to a madonna by Leonardo da Vinci. In "The Hands" figure 2, the surgeons adopt an almost identical stance to classical representations of the three kings from the east, bringing gifts at the birth of Jesus. Similarly, the ten individuals in "Concourse II" figure 3 stand around the patient in the positions commonly shown in scenes of his removal from the cross after his death.

Capener himself bought this picture from Hepworth, later donating it to the Royal College of Surgeons of England. He wrote of her hospital drawings: "Little perhaps do surgeons realise the classic beauty of their surroundings, a beauty based upon perfect architectural conditions - designed for a purpose: the focal point within a space which, whatever its shape, becomes converted visually and mentally into a circle or sphere, a group of individuals, a massing of structures all arranged with simple economy, all with a movement towards one object, one

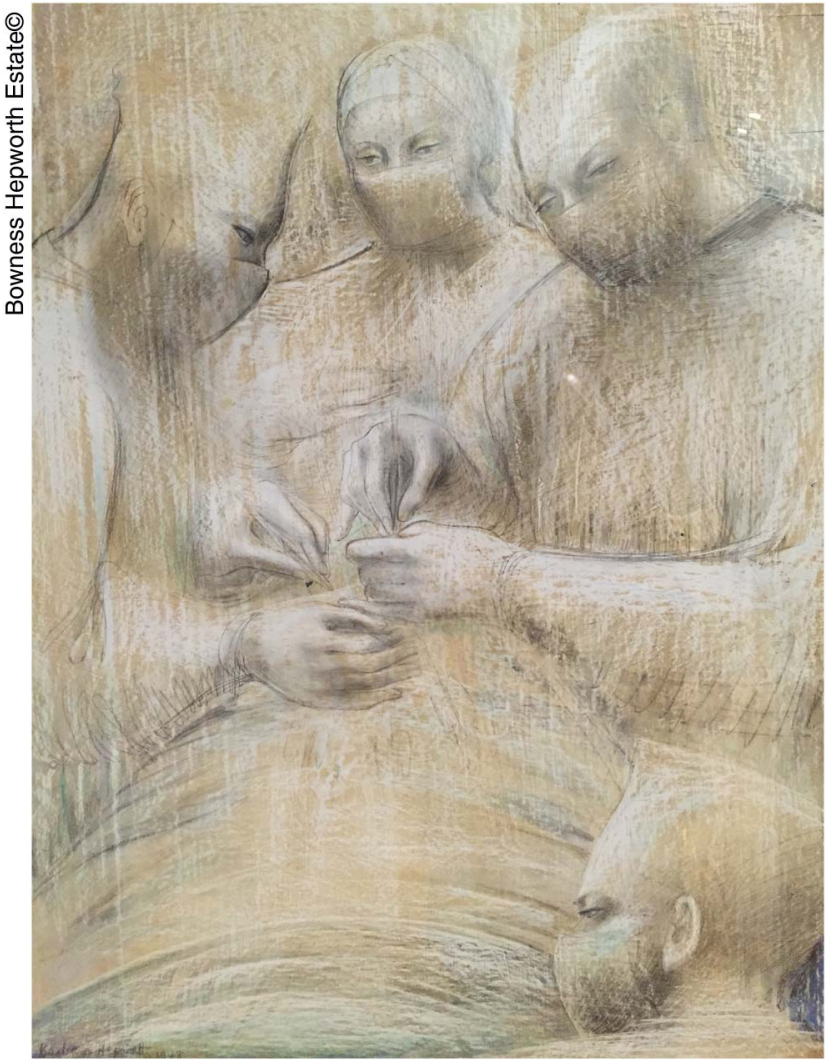

Figure 1 Concentration of Hands I, British Council Collection. 


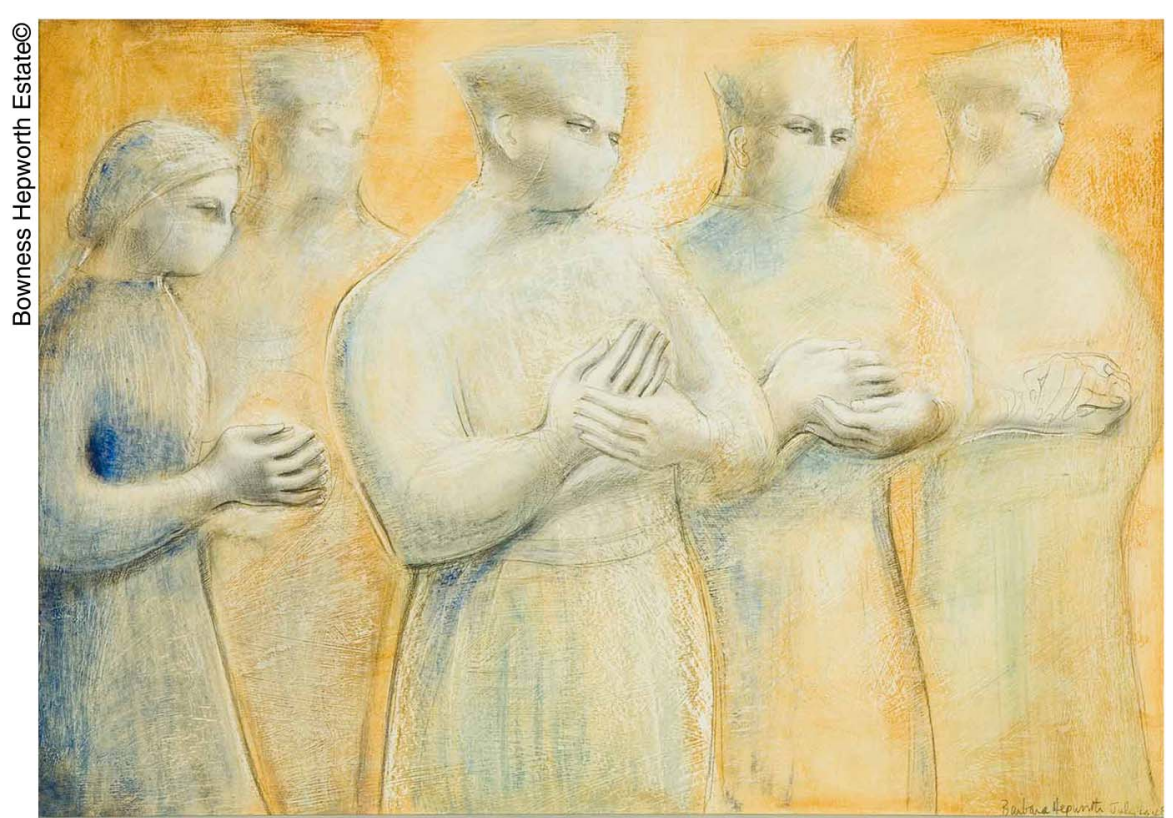

Figure 2 The Hands, Bristol Art Gallery.

purpose, all coordinated rhythmically and in harmony. Rarely has an artist been found with both stamina and vision who can perceive and portray the sincerity and harmony, the power and beauty, the

rhythm and tenderness and the simple drama of the operating theatre..."3

Hepworth's work has continued to inspire surgeons. Roger Kneebone, professor of surgical education and engagement

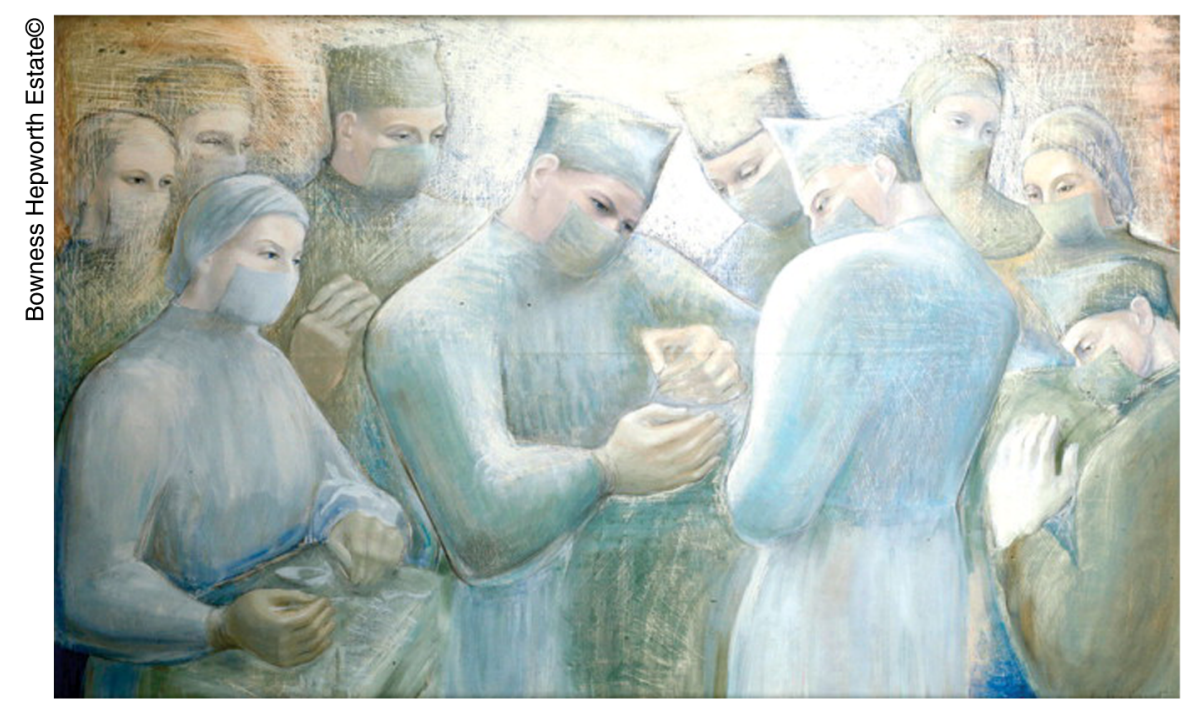

Figure 3 Concourse II, Royal College of Surgeons of England. science at Imperial College London, has used "Concourse II" to illustrate how we need the perspectives of people outside the medical profession to help us escape from what he calls the "Babel" of medical communication. Writing in the Lancet, he argues: "Because we stop registering what has become familiar, we need the 'ears of newness' of the outsider, someone who can map the vocal landscape without the preconceptions of a clinician or the involvement of a patient. We also need other sensitivities, other kinds of expertise that reach beyond the world of medicine."4 His own explorations have extended to working not only with artists and sculptors, but with jewellers, puppeteers, textile artists, tailors and others. ${ }^{5}$ As both he and Capener have understood, we need to work with people who hear what we cannot hear, but we also need the vision of people like Barbara Hepworth who are able to see what we cannot see.

Twitter Follow John Launer at @JohnLauner

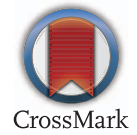

To cite Launer J. Postgrad Med J 2016;92:367-368.

Postgrad Med J 2016:92:367-368.

doi:10.1136/postgradmedj-2016-134207

\section{REFERENCES}

1 Hepworth B. The artist's view of surgery. In: Hepburn N. Barbara Hepworth: The Hospital Drawings. London: Tate Publishing, 2012:81-3.

2 Jones J. From sculpture to scalpel: Barbara Hepworth's surgical sketches. The Guardian, 24 Oct 2012. http:/l www.theguardian.com/artanddesign/2012/oct/24/ barbara-hepworth-hospital-drawings (accessed $27 \mathrm{Apr}$ 2016).

3 Capener N. Foreword to catalogue of exhibition of Barbara Hepworth's hospital drawings, Lefevre Gallery, London. In: Hepburn N. Barbara Hepworth: The Hospital Drawings. London: Tate Publishing, 2012:9.

4 Kneebone R. Escaping Babel: the surgical voice. Lancet 2014;384:1179-80. http://www. thelancet.com/journals/lancet/article/ PIIS0140-6736(14)61715-3/fulltext?rss=yes (accessed 27 Apr 2016).

5 Kneebone R. Uncertain territories. London Library Magazine 2015;28:14-17. 